\title{
CONTROLE E RESISTÊNCIA DO TRABALHO NA REESTRUTURAÇÃO PRODUTIVA DO CAPITAL NO SETOR AUTOMOTIVO
}

\author{
Fabiane Santana Previtalli
}

\begin{abstract}
RESUMO
O objetivo do trabalho é discutir a introdução de inovações técnicas e/ou organizacionais no processo de trabalho e suas implicações sobre os trabalhadores e o movimento sindical no setor automotivo no Brasil nos anos 90 . Entende-se que essas inovações envolvem novas formas de controle do capital sobre o trabalho impondo novos contornos para a dinâmica das relações de classe no capitalismo.

Palavras-chave: tecnologia, relações de classe, setor automotivo

\section{CONTROL AND RESISTANCE OF WORK IN THE PRODUCTIVE CAPITAL RESTRUCTURING AT AUTOMOTIVE SECTOR}

\begin{abstract}
The objective of this article is to discuss technological and organizational innovation and implications for workers and trade-unions at automotive sector during the $90^{\prime} \mathrm{s}$. We understand that innovation technology is linked with the class relation in the capitalism system and involve news forms of control of capital about labour and changing the dynamic class relations in the capitalism.

Kay-word: technology, class relation, automobile sector.

\section{Introdução}

Durante as últimas décadas as economias capitalistas desenvolvidas e em desenvolvimento vêm sofrendo profundas transformações. Observa-se um intenso processo de reestruturação produtiva do capital através da integração dos mercados financeiros, fundamentada, por sua vez, no novo ideário político neoliberal de livre comércio e de uma menor presença do Estado como poder regulador das relações entre capital e trabalho.
\end{abstract}


O conjunto desses elementos está implicando no retrocesso de conquistas sociais com grandes perdas para a classe trabalhadora. A reestruturação produtiva do capital tem sido potencializada pela difusão das novas tecnologias de informação associadas às novas práticas de gerenciamento e controle do processo de trabalho com a finalidade de proporcionar ao capital maior agilidade e flexibilidade diante do novo cenário competitivo mundializado. Essas transformações têm sido significativas no setor automotivo.

Sendo assim, o artigo discute num primeiro momento o processo de inovação técnica sob a lógica do capital para em seguida analisar a introdução de inovações técnicas e/ou organizacionais em duas unidades produtivas de uma empresa montadora no Brasil de forma a apreender como os trabalhadores e o movimento sindical estão respondendo às mudanças. Entendese que essas inovações envolvem novas formas de controle do capital sobre o trabalho impondo novos contornos para a dinâmica das relações de classe no capitalismo.

O grupo ao qual pertence as unidades produtivas analisadas corresponde a um de um dos principais grupos internacionais da indústria automobilística de capital majoritariamente alemão. Na segunda metade da década de 1990 o grupo intensificou o processo reestruturação de suas operações mundialmente, envolvendo fusões e aquisições, desenvolvendo novas estratégias competitivas, fundadas na focalização ${ }^{2}$, desverticalização ${ }^{3}$ e terceirização, bem como na diversificação de produtos a fim de competir em novos segmentos do mercado automotivo ${ }^{4}$. Esse processo trouxe significativas repercussões para as empresas no Brasil.

No Brasil, as unidades produtivas analisadas foram: Unidade Produtiva de Campinas (UPC), localizada em Campinas, no interior do estado de São Paulo, tendo iniciado suas atividades em 1976 e Unidade Produtiva de São Bernardo do Campo (UPSB), localizada nesta no ABC paulista, tendo sido uma das primeiras fábricas montadoras instaladas no Brasil no bojo do processo de industrialização durante a segunda metade da década de 50. A escolha de unidades em localidades distintas possibilitou a discussão das diferentes estratégias dos trabalhadores ao processo de reestruturação da empresa.

\footnotetext{
${ }^{2}$ Estratégia que consiste na definição do negócio central com conseqüente terceirização (externalização e/ou subcontratação interna) das atividades consideradas de apoio ou complementares ao negócio central.

${ }^{3}$ Processo de redução da estrutura fisica e administrativa da empresa seguido do estabelecimento de relações interfirmas horizontais e em rede.

${ }^{4}$ Previtalli, F. S. Controle e Resistência na Organização do Trabalho no SetorAutomotivo: o caso de uma empresa montadora nos anos 90. Tese de Doutorado. UNICAMP/IFCH. 2002.
} 


\section{1 - Trabalho e Inovação Técnica no Capitalismo}

A introdução de inovações tecnológicas e organizacionais no processo produtivo é uma constante no modo de produção capitalista. Marx ${ }^{5}$ foi um dos primeiros a tratar esses elementos como endógenos ao processo de acumulação desse modo de produção, analisando-os no contexto da dinâmica das relações de classes sociais do capitalismo.

Cumpre ressaltar que a teoria de Marx sobre o processo de trabalho está intimamente relacionada com sua teoria das classes sociais, sendo o conceito de classe construído a partir das formas de apropriação do trabalho excedente que, por sua vez, relaciona-se com as formas de propriedade, ou seja, a propriedade ou não dos meios de produção.

Assim, o processo de trabalho no capitalismo consiste em um processo de valorização do capital, sendo o seu objetivo principal o aumento da produção da mais valia. A questão que se coloca para o capital é a de como aumentar a produção da mais valia independentemente do prolongamento da jornada de trabalho. Esse processo torna-se possível através da redução do tempo de trabalho necessário - a parte do tempo que o trabalhador utiliza para si mesmo - e aumento do mais trabalho, que corresponde ao tempo de trabalho para o capitalista. Dessa forma o capital aumenta a força produtiva do trabalho e o processo de valorização do capital passa a se estabelecer através da mais valia relativa.

Portanto, o capital realiza a mais valia relativa através de um processo de mudanças nos meios de produção e métodos de organização do trabalho por meio da aplicação da tecnologia que, por sua vez, reduz o valor da mercadoria e da força de trabalho. Há um estímulo individual do capitalista para a redução do tempo de trabalho necessário que é o barateamento da mercadoria devido à concorrência dos demais capitalistas. A concorrência impele o capitalista a transformar as condições técnicas e sociais do processo de trabalho.

Há, assim, um estímulo intrínseco ao modo de produção capitalista que faz com que o capitalista queira investir em novas técnicas de produção, alterando as forças produtivas. Ao analisar a cooperação, a manufatura e a grande indústria, Marx demonstra como modo de produção capitalista vai ajustando, historicamente, as forças produtivas do processo produtivo à sua determinação.

Na fábrica, o processo de produção constituiu resultado direto da aplicação científica e tecnológica sobre como produzir. A máquina, que no início do 
século XIX tinha por princípio operar várias ferramentas ao mesmo tempo, significou o início do processo de automação industrial, cuja tendência apontada por Marx era de tornar-se cada vez mais intenso. Nesse período, o capital torna-se independente das habilidades do trabalho vivo. $O$ ritmo do processo e as habilidades requeridas passam a ser definidos pela máquina, havendo uma perda significativa de conteúdo do trabalho, concomitantemente a um processo de intensificação do trabalho e tornando real a subordinação do trabalho vivo ao trabalho morto.

Sendo assim, a introdução e difusão de inovações tecnológicas no processo produtivo alteram as forças produtivas no modo de produção e reprodução social capitalista, impondo a necessidade do controle sobre o trabalho na medida em que garante o caminho da produtividade, inibindo os tempos improdutivos para o capital e, portanto, garantindo a sua acumulação.

Marx considerou o conceito de controle do trabalho como central para o processo de industrialização: foi o modo pelo qual o trabalho foi subordinado ao capital. $O$ controle como prática torna-se um componente necessário às relações capitalistas de produção na medida em que os trabalhadores não fornecem totalmente sua capacidade de trabalho mas a retém por meio da responsabilidade de concepção e execução das tarefas ${ }^{6}$.

É exatamente porque o capital não pode eliminar o trabalho vivo do processo de criação de valores que ele necessita aumentar a utilização e a produtividade do trabalho. $O$ que se observa durante essa nova fase de reestruturação do capital é a redução do tempo de trabalho físico e manual direto, característico da fase de acumulação taylorista-fordista, combinada ao crescimento do trabalho multifuncional, flexivel e participativo, elementos centrais do toyotismo.

É importante destacar que em determinados momentos históricos um conjunto de mudanças, envolvendo novas práticas de organização e controle do processo de trabalho torna-se paradigmático, em função das mudanças que assinalam nas práticas industriais anteriores. Essas mudanças, resultado da dinâmica das relações de classe, acabam por promover um grande salto quantitativo e qualitativo no processo de acumulação capitalista, traçando assim novos contornos para a luta de classes, implicando em transformações

\footnotetext{
${ }^{6}$ BRAVERMAN, H. Trabalho e Capital Monopolista. Rio de Janeiro: Zahar. 1977. Para o autor a gerência busca assegurar o seu controle, primeiro determinando as tarefas individuais e depois através da direção de todo o dia de trabalho para a certeza de que as tarefas serão cumpridas. A legitimidade da gerência se assenta no discurso ideológico da aplicação cientifica e imparcial dos princípios de eficiência. No entanto o autor mostrou em seu trabalho, a despeito da retórica da eficiência científica, como o taylorismo se torna um projeto ideológico de dominação com o objetivo de assegurar a subordinação real do trabalho.
} 
significativas na estrutura social, política e cultural na sociedade determinada pela lógica do capital.

Pode-se afirmar que o processo de introdução da maquinaria descrito por Marx foi um desses momentos, assim como posteriormente o foi o processo de racionalização taylorista-fordista na indústria automotiva e desde as duas últimas décadas do século XX estão sendo as formas flexíveis de acumulação associadas às novas tecnologias de informação. Essas novas formas estão contribuindo para a redefinição do processo de controle do trabalho e, ao mesmo tempo, impondo novos desafios para a classe trabalhadora, implicando na construção de novas formas de resistência.

\section{1 - A Tecnologia como Principal Força Produtiva?}

De acordo com Freeman ${ }^{7}$ e Freeman $\&$ Perez $^{8}$, a difusão das tecnologias de informação está associada ao potencial que essa tecnologia tem de transformar os setores da economia, assim como induzir à formação de novos setores, levando ao desenvolvimento de um novo paradigma técnico-econômico ${ }^{9}$. Segundo os autores, a combinação dos processos de inovação e a formação de um novo sistema ou paradigma tecnológico é relativamente rara na economia, consistindo em um novo ciclo de desenvolvimento.

No paradigma técnico-econômico devem estar presentes fatores chaves, isto é, um tipo de insumo particular que deve cumprir três características básicas para se difundir:

(a) custos reduzidos e decrescentes;

(b) disponibilidade de fornecimento por longos periodos, condição essencial para decisões de investimentos;

(c) potencial para uso ou incorporação em novos processos e produtos, reduzindo custos e alterando qualitativamente o sistema econômico.

\footnotetext{
'FREEMAN, C. "Information Technology and Change in Techno- Economic paradigm", IN: Technical Change and Full Employment. Oxford: Blackwell. 1987.

${ }^{8}$ Freeman FREEMAN, C. \& PEREZ, C. "Structural Crises of Adjustment, Business Cycles and Investiment Behaviour", IN: DOSI et all (Eds).Technical Change and Economic Theory. London: Pinter Publishes. 1988.

"As novas tecnologias de informação baseiam-se em um conjunto de inovações, quais sejam:(a) inovações incrementais: aquelas que ocorrem sem resultado direto de uma pesquisa formal, mas através de pequenas mudanças no processo produtivo. Seus efeitos estāo mais relacionados ao crescimento da produtividade; (b) inovações radicais: aquelas cujo resultado está diretamente relacionado à pesquisa e atividades de desenvolvimento em empresa e/ou universidades e laboratórios governamentais. São mudanças totalmente novas que ocorrem no intervalo de grandes periodos; (c) novos sistemas tecnológicos: inovações incrementais e radicais articuladas que têm um grande impacto na economia.
} 
Para os autores, essa combinação de fatores se deu com a utilização da energia elétrica e do petróleo, possibilitando a generalização da produção em massa de base técnica eletromecânica. $\mathrm{O}$ regime tecnológico que predominou no pós-guerra, o taylorismo-fordismo, baseou-se nos baixos custos do petróleo e intensiva utilização de energia de materiais nos setores econômicos, particularmente o setor automotivo.

Do ponto de vista da organização difundiram-se as grandes corporações que, incluindo departamentos de pesquisa e desenvolvimento (P\&D), atuavam em mercados oligopolizados. Quanto ao processo de trabalho esse regime requeria grande número de trabalhadores pouco qualificados - o operário-massa, realizando tarefas parcelares e desprovidas de conteúdo e sentido para o trabalhador.

Segundo os autores, a partir do final da década de 70, as economias capitalistas avançadas iniciaram uma fase de transição para um novo paradigma tecnológico posto que a combinação dos fatores expostos anteriormente passou a ser encontrada na nova tecnologia de base microeletrônica ou de informação. A nova tecnologia, fundada na flexibilidade, envolve vários fatores, entre eles:
(a) uma nova prática de organização à nível da firma e da planta;
(b) nova concepção da inovação de processos, produtos e serviços com a expansão de ramos e novos setores de produção;
(c) novas formas de distribuição e consumo;
(d) novas localizações para investimentos nacionais e internacionais com tendência à concentração de grandes firmas e a diversificação de ramos de produção.

No que se refere ao trabalho, destaca-se a formação de um mercado de trabalho mais heterogêneo e qualificado, com exigências de maiores niveis de escolaridade e de novas habilidades. Essas mudanças afetam qualitativa e quantitativamente o trabalho e sua organização no processo produtivo. $\mathrm{O}$ novo paradigma técnico-econômico desenvolve-se no velho paradigma, emergindo gradualmente à medida que seus elementos ou fatores-chaves tenham satisfeito as três condições básicas já mencionadas. Cabe ressaltar que as diferenças políticas e sócio-institucionais de cada país exercem considerável influência na forma e no grau de difusão do novo paradigma. Nas palavras de Freeman \& Perez:

“(...) a formação de um novo sistema tecnológico têm conseqüências para todos os setores da economia e sua difusão é acompanhada de uma crise estrutural de ajustamento em que mudanças sócio-politicas, em âmbito institucional, são necessárias para a formação de um novo paradigma de regulação de uma nova ordem. O conjunto dessas mudanças leva à formação de um paradigma técnico-econômico ou revolução tecnológica que envolve todos 
os setores da economia, destruindo alguns e criando outros, bem como mudanças nas instituições sociais e políticas" 10 .

Portanto, há "ondas" de inovações tecnológicas que ocorrem em ciclos de cerca de 50 anos que envolvem o nascimento de um dado paradigma técnico-econômico, seu período de maior desenvolvimento e sua queda, concomitantemente à gestação de um novo paradigma. A inovação tecnológica constitui o fator desencadeador da mudança na organização do sistema econômico e institucional.

Cumpre dizer que, se por um lado os autores são responsáveis por um refinamento e extensão das formulações originais de Schumpeter no nível microeconômico, proporcionando um melhor entendimento sobre o processo de inovação técnica, por outro lado atribuem uma posição de independência e autonomia da técnica sobre as relações sócio-institucionais, conferindo um caráter determinista à análise da explicação de um processo de transformação social. A forma de correlação entre mudança técnica, no âmbito da microeconomia e "ajuste" sócio-institucional, no âmbito da macroeconomia, confere uma posição de subordinação desta última à primeira, tornando o conjunto das relações sociais, culturais e de classe dependente à atributos técnicos, quando em realidade, a técnica insere-se no contexto mais amplo do modo de produção capitalista e sua forma de acumulação.

Freeman \& Perez - e pode-se estender essa análise aos demais neo schumpeterianos - concentram sua atenção na análise das tecnologias genéricas em detrimento de estudos mais específicos sobre diferentes paradigmas produtivos, os quais somente podem ser trazidos à luz através da análise de contextos sócio-culturais particulares. Ademais, dado o pressuposto de evolucionismo e desenvolvimentismo presente na abordagem desses autores, há a tendência à interpretação do regime anterior, o taylorismo-fordismo e o Estado regulacionista como uma etapa "infeliz" no processo de evolução do capitalismo, ressaltando os elementos positivos do novo paradigma flexível.

Portanto, a inovação técnica deve ser compreendida como relacionada à diferentes práticas sociais que, por sua vez, são produto das relações de classe na luta pelo controle social do trabalho no capitalismo. Ela está assim, totalmente dependente da dinâmica de classes que se desenvolve nesse modo de organização social, sendo produto de uma "escolha" não neutra, mas relacionada à luta de classes de em um contexto social.

${ }^{10}$ Freeman \& Perez,1988 op, cit. pág. 38. 
Nesse sentido, as teses que argumentam sobre a preponderância da ciência e da técnica como forças produtivas nas sociedades contemporâneas são passíveis de críticas, pois, ao mesmo tempo, em que a ciência é liberada pelo capital para expandir-se ela é, em última instância, subordinada aos imperativos do processo de criação de valores de troca. Assim, o trabalho vivo, em conjunção com ciência e tecnologia, constitui uma complexa e contraditória unidade sob as condições do desenvolvimento capitalista posto que subordina a produção/criação dentro dos limites do seu processo de acumulação.

\section{2 - Reestruturação Produtiva e Trabalho na Unidade Produtiva de Campinas (UPC)}

Nos anos 80 a UPC deu início ao processo de reestruturação, porém ainda de forma seletiva em algumas seções. Segundo o membro da CIPA ${ }^{11}$ entrevistado, na seção de soldagem onde trabalhava, quase nada foi alterado nesse periodo, mas nas seções de ferramentaria e tornearia as mudanças foram mais significativas. Diz ele ${ }^{12}$ :

"Eles introduziram a automação (...) até então havia um monte de gente trabalhando, não havia a questão do dispositivo, as coisas eram feitas mais de forma artesanal. A empresa dependia muito do trabalhador, da pessoa fisica para fazer aquela função. Então veio a robotização e a automação. No começo dos anos 80 esse processo era ainda muito tímido, os primeiros robôs faziam só três movimentos, muito primitivo para hoje, mas na época era um avanço" (Entrevista com sindicalista membro da CIPA: 15/12/00).

Em 1989 a UPC iniciou um processo de enxugamento de pessoal que culminaria com o fechamento da produção na unidade produtiva. Nesse ano a empresa abriu um programa de demissão voluntária e ofereceu seis salários como benefício para aqueles que aderissem ao programa. Segundo os entre-

\footnotetext{
1 Comissão Interna para Prevenção de Acidentes.

12 Os trabalhadores de chão de fábrica da UPC pertencem ao Sindicato dos Metalúrgicos de Campinas e Região, o qual compreende, além da cidade de Campinas, as cidades de Americana, Indaiatuba, Nova Odessa, Hortolândia, Monte Mor, Paulínia, Valinhos e Sumaré. O sindicato está filiado à Central Única dos Trabalhadores - CUT com aproximadamente 1500 empresas e 40000 metalúrgicos na sua base, sendo 14000 deles sindicalizados. Até 1985, havia aproximadamente 70.000 metalúrgicos na base. A redução se deu em conseqüência de demissões, fechamento de empresas e terceirizações para empresas cuja categoria não se enquadra no setor metalúrgico. A diretoria do sindicato é composta atualmente por quarenta membros e se renova a cada três anos através de assembléia geral. Os indicados saem das organizações de base nas empresas. Normalmente prefere-se aquele que já é participante da Comissão Interna para Prevenção de Acidentes CIPA. Uma vez indicado, ele vai para a convenção onde é montada a chapa que concorrerá à eleição para a diretoria.
} 
vistados, aproximadamente 400 funcionários aderiram ao programa.

Nos anos 90 a empresa começou a implantar programas sistêmicos de organização e controle do processo de produção, que envolveram novas estratégias de gestão de recursos humanos, de forma a estimular o compromisso e a participação do trabalhador nas metas definidas pela empresa. Uma das primeiras técnicas desenvolvidas foi o Kaizen que visa a melhoria contínua e a redução dos desperdícios. Segundo o entrevistado:

\begin{abstract}
"Agora se fabrica de acordo com a necessidade com estoque de no mínimo uma semana. Com isso reduz-se a quantidade de pessoas porque não precisa mais tanta gente para fazer estoque para quarenta dias". Conclui ele: "assim o Kaizen é para reduzir posto de trabalho" (Entrevista com sindicalista membro da CIPA: 15/12/00).
\end{abstract}

O entrevistado destacou que juntamente com o kaizen foi introduzido o trabalho multifuncional. A empresa enfatizou o aspecto da elevação do nivel de qualificação do trabalhador. Entretanto, o que ocorria na prática era um acúmulo de funções para os que permaneciam no posto de trabalho e a demissão para os que se tornavam excedentes. Os primeiros trabalhadores atingidos pela reestruturação foram aqueles do setor de controle de qualidade.

Segundo o entrevistado, o sindicato procura discutir as mudanças e suas implicações dentro da fábrica, estimulando a militância dos trabalhadores. No entanto, essa prática tem sido bastante difícil devido à política de envolvimento da empresa e também por conta das demissões. Diante disso, a militância é construída através da formação de grupos clandestinos que são organizações de base dentro da fábrica.

Os entrevistados destacaram que na UPC antes do encerramento da produção de plataformas havia 20 pessoas que participavam do grupo clandestino e que procuravam mobilizar e conscientizar os trabalhadores. Os grupos são clandestinos por opção dos trabalhadores da UPC. Houve uma proposta da empresa em se formar uma comissão de fábrica em 1995 como acontecia na UPSB. Mas a empresa queria uma comissão paritária, sendo dois representantes dos trabalhadores e dois da empresa. "Nós não aceitamos porque a comissão tem que ser eleita pelos trabalhadores, eles é que têm que eleger e não a empresa fazer parte, por isso não teve acordo" (Entrevista com representante da CIPA e com diretor de fábrica do sindicato: 31/03/01).

Os entrevistados fizeram críticas à comissão de fábrica na UPSB:

"(...) ela deixa muito a desejar porque em algumas situações eles negociam com a empresa, eles auto-gerenciam também com a empresa, têm um lado parceiro. A gente aqui não tem esse conceito. Para nós há um divisor de classe mesmo, trabalhador está de um lado e o 
patrão está de outro e a gente não tem nada que negociar, tem mesmo é que buscar o que é nosso. Por isso mantemos a questão do grupo clandestino" (Entrevista com representante da CIPA e com diretor de fábrica do sindicato: 31/03/01).

Um ponto de divergência quanto à postura da comissão de fábrica da UPSB diz respeito à aceitação da implantação do banco de horas naquela unidade, o que não ocorria na UPC.

Em 1993 a UPC anunciou a demissão de 1200 funcionários. Segundo os entrevistados, a UPC havia já avançado na sua reestruturação, envolvendo a substituição de equipamentos e a reorganização dos cargos e tarefas. "(...) ela viu que estava sobrando pessoal e com toda essa mudança do mercado cortou 1200 companheiros" (Entrevista com representante da CIPA e com diretor de fábrica do sindicato: 31/03/01).

Em setembro de 1995 houve uma reunião entre o sindicato e a empresa para discutir o tema da Participação nos Lucros e Resultados - PRL. Nessa reunião a empresa comunicou que, por conta de um corte no pedido do cliente, teria que demitir 500 funcionários. Segundo o entrevistado:

\begin{abstract}
"(...) a empresa só comunicou o corte e não ofereceu nenhum beneficio. Então nós entramos em greve para tentar garantir os postos de trabalho que estavam sendo cortados. Ficamos aproximadamente vinte dias em greve acampados na fábrica e conseguimos algumas coisas. Alguns salários a mais de beneficio e a abertura do voluntariado porque a gente sabia que tinha gente que queria ir embora, estava para se aposentar. Foi uma briga dura". (Entrevista com representante da CIPA e com diretor de fábrica do sindicato: 31/ 03/01).
\end{abstract}

Em 1996 os funcionários estavam em férias coletivas em casa e a empresa comunicou novas demissões através de uma carta. Nas palavras do entrevistado:

\begin{abstract}
“(...) nós achamos uma covardia. O sindicato foi comunicado, nós fomos para a fábrica e levamos nossos familiares. Fizemos uma grande assembléia e novamente acampamos na fábrica por mais ou menos dezessete dias. Mas desta vez já não conseguimos muita coisa, o processo já era mesmo mais irreversivel porque a empresa estava terceirizando a fabrica. ção do monobloco [as carrocerias dos ônibus], ficou só com a fabricação da plataforma" (Entrevista com representante da CIPA e com diretor de fábrica: 31/03/01). Aproximadamente 2000 funcionários foram demitidos nesse período ${ }^{13}$.
\end{abstract}

\footnotetext{
${ }^{13}$ A UPC sofreu no periodo de 1990 - 1998, uma redução de $58 \%$ no número de funcionários indiretos (mensalistas e gerentes) e de $81 \%$ no número de trabalhadores de chão de fábrica (horistas).
} 
Os movimentos grevistas de tomada da fábrica foram iniciados pelo grupo clandestino que considerou inviável a mobilização fora da fábrica porque havia outras empresas dentro do espaço físico da UPC, em regime de sublocação. Não seria possível o controle da entrada dos funcionários da UPC porque poderiam estar misturados aos trabalhadores das outras empresas.

No início de 2000, a empresa anunciou que estava suspendendo todas as atividades de produção na UPC e transferindo-as para a unidade produtiva de São Bernardo do Campo. "(...) eles falaram para a gente em 2000, mas já sabiam disso antes, nós já sabíamos que algo muito drástico iria acontecer por causa da terceirização do monobloco e das demissões (...) achávamos que iria fechar mesmo" (Entrevista com representante da CIPA e com diretor de fábrica: 31/03/01).

Segundo os entrevistados, a empresa procurou o sindicato para um acordo de transferência ${ }^{14}$. Na avaliação dos entrevistados, era a única coisa que poderia ser feita, ou seja, negociar sobre a transferência já que a empresa não trabalhava com a hipótese de manter a produção em Campinas. Em suas palavras:

"(...) o processo de transferência foi ruim porque foram perdidos os postos de trabalho aqui [na UPC]. Aqueles que concordaram em ir tiveram algumas vantagens financeiras, mas muita gente ficou desempregada mesmo. Dos 400 trabalhadores da produção, aproximadamente $80 \%$ aceitou a transferência por medo de ficar sem emprego. Quem não aceitou ficou desempregado aqui em Campinas" (Entrevista com representante da CIPA e com diretor de fábrica: 31/03/01).

De acordo com os entrevistados, não houve mudança no processo de trabalho de forma que os trabalhadores continuaram a fazer as mesmas tarefas que faziam na UPC. Entretanto, eles ressaltaram que o ambiente de trabatho na UPSB era pior. Em suas palavras:

“(..) os equipamentos e os companheiros foram.para um prédio mais antigo e sem muita ventilação. O espaço físico é pequeno para realização do trabalho, dificultando a locomoção das pessoas e também das peças. O pessoal está reclamando bastante e a situação está crítica e nós estamos junto com a comissão de fábrica de lá brigando para tentar melhorar essa situação" (Entrevista com representante da CIPA e com diretor de fábrica: 31/ 03/01).

\footnotetext{
${ }^{14}$ A transferência foi dividida em três fases. A primeira fase ocorreu logo no início de 2000 , envolvendo cerca de oitenta trabalhadores. A Segunda fase foi concluida em dezembro de 2000 , envolvendo aproximadamente 120 trabalhadores. A terceira fase estava prevista para ser concluida no início de 2001.
} 
Na verdade, a transferência dos trabalhadores se fez necessária em função do processo de particularidades do processo de trabalho, essencialmente manual e, portanto, mais dependente dos conhecimentos e habilidades do trabalhador sobre o mesmo.

\section{3 - Reestruturação Produtiva e Trabalho na Unidade Produtiva de São Bernardo do Campo (UPSB)}

A reestruturação produtiva nos anos 90 , envolvendo o enxugamento das atividades das empresas assim como o fechamento de unidades produtivas, teve grande impacto sobre a geração de emprego na região do $A B C$ paulista. As empresas argumentaram que os custos com a força de trabalho estavam altos em comparação com outras regiões do país. Assim, a possibilidade de uma força de trabalho mais barata e, cumpre dizer, uma menor mobilização do movimento sindical, foram os fatores que contribuíram para a realocação espacial das empresas para regiões sem tradição industrial ${ }^{15}$.

Em meados da década de 90 a fábrica foi dividida em 4 unidades de negócio de forma a obter flexibilidade organizacional. As unidades de negócio ficaram assim definidas: (1) motores; (2) eixos, (3) cabinas e (4) montagem de veículos. A mudança, segundo o entrevistado, auxiliou na redução dos niveis hierárquicos e facilitou a integração entre serviços de apoio à produção (programação, manutenção e planejamento) e a área produtiva. As áreas de logística e de qualidade que estavam centralizadas foram descentralizadas para as unidades de negócios.

Até a década de 80, o lay out da fábrica era dedicado e linear, passando a ser semi-linear na montagem e celular na produção devido as características específicas de cada processo. Os subcomponentes passaram a ser manufaturados em células próximas e ao longo da linha. Com as mudanças foi reduzido o tempo ocioso que se tinha na movimentação de materiais e de manuseio de peças. "(...) a mudança deu flexibilidade à linha e permitiu uma rápida troca de

\footnotetext{
${ }^{15}$ A UPSB está localizada na região do Grande $\mathrm{ABC}$ paulista, berço do processo de industrialização no Brasil durante as décadas de 50 e 60 , tradicional reduto da indústria automotiva no país. A região reúne sete municipios, quais sejam: São Caetano do Sul, Mauá, Ribeirão Pires, Santo André, São Bernardo do Campo, Diadema e Ribeirão da Serra com 2,2 milhões de habitantes, sendo o terceiro mercado consumidor do país, atrás de São Paulo e Rio de Janeiro. A região representa ainda $13,8 \%$ da atividade industrial do estado de São Paulo, apesar do intenso processo de reestruturação produtiva pelo qual passou particularmente durante a segunda metade da década de 80 e ao longo dos anos 90 . Esse processo envolveu a saída de muitas empresas da região, especialmente do setor produtivo, ao mesmo tempo em que se presenciou o crescimento do setor de prestação de serviços. Em 1990 a taxa de desemprego da população economicamente ativa na região era de 9,3\%, passando para $19,9 \%$ em 1999 .
} 
ferramentas; passou-se a produzir mais de um produto em uma mesma linha" (Entrevista com gerente de qualidade da UPSB: 21/03/01).

O entrevistado afirmou também que os investimentos em automação dos equipamentos haviam aumentado na década de 90 em relação ao período anterior e era realizado para obter-se maior qualidade na produção e redução de custo fixo. A prioridade foi de investimentos em máquinas de produção automatizadas e multifuncionais. Ele destacou ainda que a conseqüência mais imediata foi o aumento da produtividade com um menor número de trabalhadores.

Junto com as mudanças no lay out e nos equipamentos, ocorreram as mudanças organizacionais. Houve a redução de niveis hierárquicos e do trabalho multifuncional nas células de manufatura. A organização não obedecia mais a uma organização hierárquica, mas sim a um grupo funcional onde os próprios operários designavam um líder escolhido por um grupo. Isso foi bastante importante nas unidades produtivas. Para introduzir e desenvolver essas mudanças a empresa investiu em programas de conscientização que estimulassem o funcionário ao comprometimento e à melhoria contínua.

Um dos programas mais enfatizados na gestão participativa foi o Kaizen. O objetivo foi desenvolver uma cultura de melhoria contínua. Segundo o entrevistado, os resultados foram positivos, o que permitiu que a UPSB fosse uma das melhores dentro do grupo mundial na parte de produção em 2000. Os outros programas/atividades que fizeram parte da reestruturação visando a gestão participativa durante e década de 90 foram:
(a) reuniões internas para informação e esclarecimento;
(b) treinamento de conscientização da qualidade;
(c) treinamento operativo (on the job);
(d) treinamento nas ferramentas da qualidade;
(e) uso efetivo do CEP;
(f) grupos operativos para a solução de problemas (CCQs)
(g) remuneração variável (participação nos resultados);
(h) monitoramento através de emprego de indicadores.

Para que a gestão participativa obtivesse o resultado esperado pela empresa, foi necessário desenvolver estratégias conjuntas para conseguir a confiança do trabalhador para que ele fosse motivado a participar. Nesse sentido, a empresa investiu em novos meios de comunicação com o trabalhador, como o circuito interno de TV e os jornais oficiais do grupo nos quais são veiculadas notícias positivas sobre o grupo e a empresa. Observou-se que todo o processo de reestruturação produtiva é informado como uma "necessidade do mercado" e um imperativo para o desenvolvimento. 
O processo de reestruturação envolveu a redefinição das responsabilidades do funcionário no sentido de torná-lo multifuncional. Por conta dessas mudanças foram reduzidas as funções de chefia e mestria. Em 1990 existiam oito níveis hierárquicos na produção, que foram reduzidos para cinco em 2000.

A reestruturação envolveu também a questão da qualidade na empresa. Em 2001 o setor de qualidade estava organizado em dois grandes blocos. O primeiro relacionava-se ao aspecto estratégico da qualidade e envolvia as atividades de definição da estratégia corporativa do padrão de qualidade da empresa, bem como dos requisitos e metas a serem atingidos. As metas eram definidas anualmente, tendo um acompanhamento mensal para monitoramento e envolviam itens como: grau de satisfação do colaborador (funcionário) e do cliente, nível de estoques e índice de rejeição entre outros. O segundo bloco consistia no aspecto operacional da qualidade, isto é, no desenvolvimento e aplicação das metas definidas, envolve determinadas ferramentas de controle e gestão como o CEP (Controle Estatístico de Processo).

Quanto as atividades de qualidade desenvolvidas pelos operários da produção, o entrevistado explicou que aquelas relacionadas à definição dos procedimentos de qualidade ainda ficavam a cargo dos técnicos, enquanto os operadores faziam as atividades de inspeção, tendo havido intensificação das atividades em alguns casos a partir dos anos 90 (Quadro 1). Ou seja, os

\begin{tabular}{|c|c|c|c|c|}
\hline \multicolumn{5}{|c|}{$\begin{array}{l}\text { QUADRO 1 } \\
\text { Atividades desenvolvidas pelos Operários da Produção } \\
\text { Antes e Depois da Reestruturação dos Anos } 90\end{array}$} \\
\hline Atividades & Já faziam & Fazem mais & $\begin{array}{l}\text { Só Fazem } \\
\text { agora }\end{array}$ & Não fazem \\
\hline 1. Inspeçāo visual do produto & $\mathrm{X}$ & $\mathrm{x}$ & & \\
\hline $\begin{array}{l}\text { 2. Inspeção com } \\
\text { instrumento de medida }\end{array}$ & $\mathrm{X}$ & $\mathrm{x}$ & & \\
\hline 3. Preencher cartão do CEP & & & $\mathrm{x}$ & \\
\hline $\begin{array}{l}\text { 4. Manutençāo preventiva } \\
\text { ou de rotina }\end{array}$ & $\mathrm{X}$ & $\mathrm{x}$ & & \\
\hline $\begin{array}{l}\text { 5. Produzir dentro do } \\
\text { prazo programado }\end{array}$ & $\mathrm{x}$ & $\mathrm{X}$ & & \\
\hline $\begin{array}{l}\text { 6. Participação em grupos ou } \\
\text { em circulos de qualidade }\end{array}$ & & & $\mathrm{x}$ & \\
\hline $\begin{array}{l}\text { 7. Capacidade de efetuar } \\
\text { funçôes diferentes }\end{array}$ & & & $\mathrm{X}$ & \\
\hline 8. Operar mais que uma máquina & & & $\mathrm{X}$ & \\
\hline 9. Preparar a máquina & & & $\mathrm{x}$ & \\
\hline 10. Troca de ferramenta & & & $\mathrm{X}$ & \\
\hline
\end{tabular}

Fonte: Previtalli (2002). 
operadores tiveram um acréscimo de tarefas, envolvendo a qualidade mas não decidiam sobre elas, o que ficara sob a responsabilidade de um outro funcionário.

A reestruturação exigiu, segundo o entrevistado um novo perfil do funcionário, agora chamados de "multiplicadores internos".

“(...) são pessoas formadoras de opinião dentro do grupo e que transmitem os conhecimentos para os operários da produção. Normalmente são líderes para o grupo. São pessoas escolhidas e são formadas por meio de várias ferramentas, entre as quais se destacam as palestras" (Entrevista com gerente de qualidade da UPSB: 21/03/01).

Entre as novas qualificações e habilidades sugeridas por esta pesquisa, o entrevistado destacou as seguintes, classificando-as numa escala de 1 a 10 (Quadro 2).

\begin{tabular}{|l|c|}
\hline \multicolumn{2}{|c|}{$\begin{array}{c}\text { QUADRO 2 } \\
\text { Habilidades e Qualificações do Trabalhador Requeridas pela UPSB }\end{array}$} \\
\hline \multicolumn{1}{|c|}{ Habilidades } & Pontos \\
\hline 1. Saber ler e escrever & 10 \\
\hline 2. Ter noçōes de matemática básica & 10 \\
\hline 3. Ter noçōes de estatistica & 5 \\
\hline 4. Saber interpretar desenhos & 10 \\
\hline 5. Ser capaz de trabalhar em grupo & 10 \\
\hline $\begin{array}{l}\text { 6. Ser responsável: cumprir bem uma tarefa, dar sugestões de melhoria, olhar o ambiente dentro } \\
\text { do aspecto da Qualidade Total* }\end{array}$ & 10 \\
\hline 7. Seguir instruçōes & 5 \\
\hline 8. Desejar aprender novas habilidades & 8 \\
\hline 9. Ter iniciativa & 8 \\
\hline 10. Ser participativo: dar sugestões; ter iniciativa & 8 \\
\hline
\end{tabular}

Fonte: Previtalli (2002).

De acordo com um gerente de produção entrevistado, uma das principais mudanças na fábrica foi a introdução do trabalho em grupo. Até meados da década de 90 os postos de trabalho eram definidos de forma estreita, mas a empresa esperava que os trabalhadores, quando solicitados, realizassem tarefas fora desta definição. A partir de1995 foram sendo introduzidos os primeiros grupos de trabalho. 
A introdução dessa forma de organização do trabalho na fábrica teve como objetivo, segundo o entrevistado, envolver mais o trabalhador com a empresa, tornando-o responsável e motivado. A empresa visava atingir as seguintes metas com a introdução do trabalho em grupo: (a) aumentar a flexibilidade devido a multifunção, (b) aumentar o grau de comprometimento dos trabalhadores com as metas da empresa, (c) reduzir as atividades de refugo e retrabalho e (d) reduzir o absenteísmo.

Vale dizer que a UPSB possuía dois processos produtivos chaves. $O$ primeiro era o desenvolvimento de novos produtos. Esse processo envolve os funcionários das áreas de planejamento, engenharia e design até sua colocação na linha de produção e está relacionado à definição do processo produtivo. É nesse processo, que envolve o desenvolvimento de produto, que a UPSB enfatizava a introdução do trabalho em grupos e das equipes multifuncionais.

O segundo processo é o de produção do produto já definido. Esse é um processo padrão e a UPSB optou por definir os postos de trabalho de forma mais estreita sem a introdução do trabalho em grupos. Esse segundo processo envolve uma rotina de produção que é produzir de acordo com especificações determinadas no primeiro processo.

O trabalho em grupo teve sua implantação na UPSB em dezembro de 1995 a partir de um projeto piloto que visou a implantação de seis grupos. Os grupos foram oficializados com a eleição, pelos pares, de porta-vozes (lideres) e distribuídos da seguinte forma: dois grupos na área de usinagem de motores; dois grupos na montagem de cabinas e dois grupos na área de fabricação de cabinas brutas. $O$ grupo tendia ter de 6 a 10 trabalhadores.

As primeiras discussões sobre a nova forma de organização do trabalho começaram em 1991, pela direção da empresa. Após a decisão favorável da diretoria sobre a implementação, o passo seguinte foi comunicar o Sindicato dos Metalúrgicos do $\mathrm{ABC}$ e a Representação Interna de Empregados, a comissão de fábrica.

Para que o sindicato conhecesse e aderisse à nova proposta de relacionamento entre capital e trabalho, foram programadas duas viagens à Alemanha, realizadas em novembro de 1993 e janeiro de 1994, com representantes da empresa e do sindicato, com o objetivo de mostrar ao sindicato como era o trabalho em grupo nas fábricas da Alemanha. Também participaram das visitas representantes do Departamento Intersindical de Estatística e Estudos Sócio-Econômicos (DEESE) que assessorou o sindicato dos metalúrgicos do $\mathrm{ABC}$ nas negociações.

Em seguida iniciou-se o treinamento de supervisores e mestres nas técnicas de gestão participativa. Esse treinamento objetivou conscientizar 
esses niveis sobre a nova forma de organização do trabalho, levando em conta a necessidade de mudanças de paradigmas até então vigentes.

A implantação efetiva dos grupos ocorreu em 4 fases, quais sejam:

Fase 1: definição da área em que o trabalho em grupo seria implementado, observando os seguintes aspectos:

Fase 2: treinamento para os funcionários com o objetivo de instrumentalizá-los com os novos conceitos e técnicas, visando o seu comprometimento para o sucesso do projeto. $\mathrm{O}$ treinamento teve a duração de 28 horas, dividido em 7 módulos, quais sejam:

Fase 3: efetivação do grupo no local de trabalho.

Fase 4: manutenção dos grupos dentro da proposta de sua implantação.

Essa fase envolveu reuniões mensais de monitoramento para dar suporte aos líderes e mestres nas soluções de problemas. Participavam o gerente de departamento, supervisores, mestres, líderes, representantes dos empregados, analista de pessoal e coordenadores do trabalho em grupo.

Com o ganho de autonomia os grupos passaram a adquirir novas atividades antes exercidas pelo mestre, tais como: controle de estoques, pequenas manutenções, organização do trabalho, sugestões de melhorias, escalas de férias e folgas. E o mestre passou a exercer atividades estratégicas como redução de desperdícios e de custos e aumento da qualidade e produtividade.

De acordo com o gerente de produção entrevistado, os líderes são operários da produção e têm uma recompensa financeira. Quem define sobre a implantação do grupo é a chefia da área. Os grupos estão mais presentes no desenvolvimento de projetos. A organização/coordenação das tarefas no interior das equipes ocorre através de rodízios. É realizado um treinamento comportamental da equipe para que cada colaborador perceba os valores do grupo de trabalho.

Ainda segundo o entrevistado, as metas de produção são traçadas e são avaliadas através de indicadores de produção que são medidos antes e depois da introdução do grupo de trabalho. Os indicadores são: produtividade, qualidade e absenteísmo, entre outros. "O acompanhamento é mensal. Avaliando o absenteísmo é possivel verificar o grau de comprometimento da pessoa" (Entrevista com gerente de produção da UPSB: 29/03/01).

A participação dos membros dos grupos na programação da produção não ocorre. Segundo o entrevistado os grupos recebem uma meta já determinada, decidindo somente sobre como será desenvolvida no processo.

Sobre o líder, o entrevistado afirmou que ele atua como porta voz, não tendo poder disciplinatório. A disciplina é responsabilidade da mestria. Porém, "(...) se alguém do grupo falta, a redistribuição da tarefa tem que ser outra, o que 
pode sobrecarregar o grupo. O lider atua alertando para esse fato. Na verdade, o próprio grupo acaba questionando um pouco essa falta" (Entrevista com gerente de produção da UPSB: 29/03/01).

$\mathrm{Na}$ verdade, a empresa delega ao grupo de trabalhadores o controle sobre si mesmo e os companheiros. Daí a ênfase da UPSB no treinamento comportamental dos trabalhadores, visando o seu comprometimento. Podese dizer que essa é a mudança significativa no trabalho em grupo. Quanto à tomada de decisões, esta é bastante restrita. $O$ grupo não têm o poder de interromper a produção quando necessário ou de opinar na contratação de novos empregados. A autonomia se restringe à organização das tarefas. Quanto a poder interromper a produção se necessário, deve-se consultar a mestria.

Segundo o entrevistado, a implantação do trabalho em grupo neutralizou parcialmente a função da comissão de fábrica. Em suas palavras:

“(...) no momento em que a empresa dá mais autoridade ao trabalhador ele se sente mais confiante em estar discutindo sem a necessidade de requerer um representante para tal. $\mathrm{Na}$ medida em que a empresa fornece instrumentos de participação para os trabalhadores como é o caso do trabalho em grupo, esse trabalhador não precisa mais de representantes para defender os interesses dele porque ele se sente mais participativo. Ele já possui um canal de comunicação que é o grupo e o líder para discutir assuntos do trabalho" (Entrevista com gerente de produção da UPSB: 29/03/01).

\section{1 - A Adesão da Comissão de Fábrica à Reestruturação}

Diante das transformações econômicas e sociais na região, o movimento sindical na região do $\mathrm{ABC}$ começou a aceitar a neociação sobre as formas de flexibilização nas relações de trabalho, visando principalmente a manutenção do emprego ${ }^{16}$. Na UPSB, a comissão de fábrica que representa os trabalhadores no local de trabalho está em consonância com as novas diretri-

${ }^{16}$ Os trabalhadores de chão de fábrica da UPSB pertencem ao Sindicato dos Metalúrgicos do ABC, filiado a CUT. O processo de reestruturação das empresas no $A B C$, envolvendo a realocação geográficas das plantas com graves conseqüências para o emprego na região, causou fortes implicaçōes nesse movimento sindical e nas formas de resistência dos trabalhadores na região. Em 1987, o sindicato possuía 203.111 trabalhadores em sua base. Em 1996 esse número foi reduzido para 120.681 trabalhadores, significando uma queda de $40,6 \%$ no periodo considerado. A redução no nivel do emprego na região foi um dos fatores que levou ao redirecionamento das estratégias de resistência dos trabalhadores na região do $A B C$. Uma das implicações mais marcantes do redirecionamento das estratégias de resistência foi a redução do número de greves realizadas pela classe trabalhadora. Em 1990 ocorreram 169 greves no pais e em 1997 esse número caiu para 59, uma redução de $35 \%$ no período considerado. Cumpre dizer que também o número de grevistas no pais foi drasticamente reduzido. Em 1990, 804.311 trabalhadores realizaram greves, enquanto em 1997 o número de grevistas foi 80.355 , uma redução de $90 \%$ no período considerado. Ademais as reivindicaçōes não eram, em sua maioria, por aumentos de salários como ocorria na década de 80 , mas por pagamentos dos mesmos, especialmente nas pequenas empresas. 
zes do movimento sindical do $\mathrm{ABC}$. De acordo com um representante da comissão entrevistado:

"(...) a comissão de fábrica decidiu negociar porque hoje isso significa intervenção. Vimos que a reestruturação era irreversivel, mas que era possivvel intervir através da intervençã.. Nós optamos pela negociação. Não traz beneficio, mas se não interferir, [a reestruturação] traz prejuizo para os trabalhadores" (Entrevista com membros da Comissão de Fábrica: 02/02/01).

Segundo os entrevistados, a comissão de fábrica tem se pronunciado em várias questões que antes eram apenas prerrogativa da empresa, entre elas: turno de trabalho, horário, jornada de trabalho, salários e benefícios, nível de emprego, mudança organizacional, PLR, terceirização, e a implantação do trabalho em grupo.

Quanto ao trabalho em grupo, os entrevistados afirmaram que é UPSB determina as metas de produção e os recursos (máquinas, ferramentas, espaço físico, custos e qualidade). O grupo decide como fazer o trabalho, o que envolve a divisão das tarefas e a forma do rodízio. O grande benefício, segundo o entrevistado é que "(...) tira o chefe de cima, dando a oportunidade de controle do trabalho e ganhos salariais maiores" (Entrevista com membros da Comissão de Fábrica: 02/02/01).

Assim, embora a autonomia e o poder de decisão do grupo sejam limitados, a menor interferência das chefias no chão de fábrica é um dos aspectos mais ressaltados pelos entrevistados. Ademais, ainda segundo os entrevistados, os trabalhadores que participam dos grupos não desejam retornar às antigas atividades dentro da empresa.

Os entrevistados ressaltaram que a grande questão da comissão de fábrica hoje diz respeito às variações na produção. Eles afirmaram que quando há queda na produção a empresa transfere o trabalhador para outras tarefas. No entanto, quando ocorre aumento na produção não são trazidos novos trabalhadores, o que intensifica o trabalho.

Segundo os entrevistados, as negociações com a empresa têm sido o caminho para a resistência dos trabalhadores e as estratégias que a comissão de fábrica da UPSB são no sentido de buscar maior interferência no processo. Questionado sobre as decisões que a empresa toma sem o envolvimento da comissão de fábrica e do sindicato, os entrevistados afirmaram que isso ocorre, mas esse fato não descaracteriza a ação dos trabalhadores. Nas palavras do entrevistado:

"(...) sabemos muito bem que a empresa é que tem o controle e que dita as regras do jogo. O nosso desafio é interferir e negociar o maior número de mudanças possivel 
(...) quando ela [a UPSB] toma uma decisão e nós não concordamos, procuramos negociar (...)" (Entrevista com membros da Comissão de Fábrica: 02/02/01).

\section{Considerações Finais}

As formas de resistência da classe trabalhadora são resultado da dinâmica das classes no capitalismo e assumem diferenças características ao longo de sua trajetória histórica, que vão da oposição radical em determinados momentos, ao compromisso com o capital em outros momentos. Portanto, os trabalhadores também engendram um processo de reestruturação de forma a responder às novas exigências da luta de classes, redefinindo as formas e o conteúdo das reivindicações da força de trabalho e, ao mesmo tempo, exigindo novas formas de articulação. É no local de trabalho que as relações sociais coercitivas do capital fornecem um terreno crucial na organização coletiva e na luta de classes através da organização e controle sobre o processo de trabalho.

Com o avanço da reestruturação produtiva ao longo dos anos 90, o combate e a crítica às políticas de reestruturação adotadas pelas empresas tenderam a dar lugar a um processo de adaptação e adequação do movimento sindical a nova ordem do capital. As estratégias de resistência da classe trabalhadora passaram a priorizar a negociação com as empresas, visando à defesa e à manutenção do empregọ.

Vale dizer que a retração à ofensiva do capital diante das novas formas de controle do processo de trabalho tem sido uma tendência mundial. Entretanto há ainda correntes dentro do movimento sindical que resistem ideologicamente à ofensiva do capital, embora encontrando sérias dificuldades para manter essa postura classista. Este é o caso dos trabalhadores da UPC. Na UPSB, a estratégia de resistência dos trabalhadores, via comissão de fábri$\mathrm{ca}$, tenderam a assumir características mais conciliatórias, seguindo uma tendência majoritária dentro do movimento sindical da região do $\mathrm{ABC}$ paulista.

Para autores como Bresciani ${ }^{17}$, a experiência de negociação entre empresas e sindicatos consiste em um avanço nas relações entre capital e trabalho no país. No entanto, cumpre dizer que a negociação ocorre via acomodação dos trabalhadores à ofensiva da reestruturação produtiva das empresas. De acordo com Alves ${ }^{18}$, a nova estratégia, que denomina "influência propositiva" é uma forma de intervenção sindical de eficácia relativa e de

\footnotetext{
${ }^{17}$ Bresciani, 2001 BRESCIANI, L. P. O Contrato da Mudança: a inovação e os papéis dos trabalhadores na indústria brasileira de caminhões. Tese de Doutorado. Campinas: IG/UNICAMP. 2001. ${ }^{18}$ Alves, G. O Novo e Precário 2000 O Novo (e Precário) Mundo do Trabalho: reestruturação produtiva e crise do sindicalismo. São Paulo: Boitempo. 2000.
} 
conteúdo neocorporativo predominante nessa nova fase da reestruturação produtiva do capital, cuja ênfase se dá sob as formas de controle pautadas no toyotismo.

A adoção de práticas mais colaboracionistas, como tem ocorrido na região do $\mathrm{ABC}$, refletem em grande medida, a necessidade dos trabalhadores se adaptarem a um contexto marcado pela realocação geográfica das empresas e pelo conseqüente fechamento de postos de trabalho constituindo portanto, uma estratégia de resistência defensiva. Entretanto, essa estratégia está longe de constituir um avanço nas relações entre capital e trabalho na medida em que os trabalhadores tendem a assumir o discurso da lógica do capital e da necessidade da adaptação, perdendo seus vínculos de classe e de contraofensiva propositiva ao modo de produção capitalista. 